\title{
MOVIMENTAÇÃO DE CÁTIONS EM AMOSTRAS DE UM LATOSSOLO VERMELHO-AMARELO INCUBADAS COM DUAS FONTES DE CÁLCIO'
}

\author{
Paulo Guilherme Salvada Wadt²*; Lúcia Helena de Oliveira Wadt ${ }^{3}$ \\ ${ }^{2}$ Meta Agroflorestal, Chácara Primavera, C.P. 224 - CEP: 13730-970 - Mococa, SP. \\ ${ }^{3}$ Pós-Graduanda do Depto de Genética - ESALQ/USP, C.P. 9 - CEP: 13418-900 - Piracicaba, SP. \\ *e-mail: pgswadt@mandic.com.br
}

RESUMO: Estudou-se a movimentação de cátions alcalinos e alcalinos terrosos (CAAT) em colunas de solo arranjadas com amostras de Latossolo Vermelho-Amarelo, álico, coletadas a profundidade de 0 a $5 \mathrm{~cm}$ sob dois tipos distintos de cobertura, floresta secundária e grama batatais (Paspalum notatum $L$.), as quais foram superpostas em potes plásticos à amostras do horizonte Bw, da mesma unidade de solo. Aplicaram-se carbonato de cálcio, sulfato de cálcio ou a mistura das duas fontes de cálcio às amostras superficiais, as quais foram colocadas a incubar e depois submetidas a sete aplicações de água destilada, na taxa de 1 volume-poro por semana, durante sete semanas consecutivas. 0 lixiviado foi recolhido semanalmente e analisado para cálcio, magnésio, potássio e sulfato solúveis. Nos solos, fizeram-se determinações dos teores de cálcio, magnésio e potássio trocáveis, e a determinação da acidez potencial a pH 7,0. A aplicação de sulfato de cálcio favoreceu o processo de lixiviação de potássio e magnésio, enquanto que a aplicação de carbonato de cálcio minimizou a lixiviação. Concluiu-se que a utilização de sulfato de cálcio para a correção da deficiência de cálcio em subsolos ácidos deve ser acompanhada necessariamente da aplicação de carbonato.

Palavras-chave: carbonato de cálcio, sulfato de cálcio, lixiviação, gesso agrícola, calagem

\section{CATION MOVEMENT IN SAMPLES OF A RED-YELLOW LATOSOL INCUBATED WITH TWO CALCIUM SOURCES}

ABSTRACT: The movement of cations in an Oxisol (alic, Red-Yellow Latosol) was studied. Samples were collected within the first $5 \mathrm{~cm}$ of the topsoil from two types of plant cover (grass and secundary forest), and placed in plastic pots over samples of an Oxic horizon from the same soil. To the superficial samples, Calcium Carbonate, Calcium Sulphate, or the mixture of both were applied, incubated, followed by seven applications of distilled water, at the rate of one pore-volume a week. The leachate was collected every week and was analysed for soluble calcium, magnesium, potassium and sulphate. Evaluations of exchangeable calcium, magnesium and potassium, and of the potential acidity in $\mathrm{pH} 7.0$ were performed in the soil. It was observed that the sulphate promoted a loss of potassium and magnesium, while the calcium carbonate minimized the loss. It was concluded that the use of calcium sulphate to correct calcium deficiency in acid subsoils has to be followed by the application of carbonate.

Key words: calcium sulphate, calcium carbonate, leaching, gypsum, liming

\section{INTRODUÇÃO}

É conhecido que baixos níveis de $\mathrm{Ca}^{+2}$ trocável nos subsolos ácidos reduzem o crescimento radicular, que pode ser problema principalmente em períodos de deficit hídrico (Ritchey et al., 1980). A aplicação de elevadas doses de calcário, pode promover o movimento descendente de $\mathrm{Ca}^{+2}$ (Raij et al., 1982; Quaggio et al., 1982b). Contudo, na maioria dos casos o
$\mathrm{Ca}^{+2}$ apresenta baixa mobilidade quando aplicado junto ao carbonato e outras bases (Gargantini et al., 1982), o que tem levado à recomendação da aplicação de sulfato de cálcio para a promoção do movimento descendente de $\mathrm{Ca}^{+2}$ (Reeve \& Sumner, 1972; Sumner et al., 1986) e melhoria do ambiente radicular para o crescimento das raízes, mesmo em regiões de baixa pluviosidade (McLay et al., 1994).

\footnotetext{
${ }^{1}$ Parte da Dissertação de Mestrado do primeiro autor apresentada à UFRRJ - Seropédica, RJ.
} 
A utilização do sulfato de cálcio apresenta o incoveniente de intensificar a movimentação descendente de outros elementos, notadamente $\mathrm{K}^{+}$ e $\mathrm{Mg}^{+2}$ (Quaggio et al., 1982a; Pavan et al., 1984).

A maior efetividade do sulfato de cálcio em aumentar os teores de $\mathrm{Ca}^{+2}$ na camada subjacente à camada de aplicação é bastante conhecida (Ririe et al., 1952; Reeve \& Sumner, 1972). A elevação do $\mathrm{pH}$ nas camadas subjacentes à aplicação de carbonato de cálcio, acompanhado de aumentos nos teores de cálcio e, ou, magnésio trocáveis também tem sido observada (Ririe et al., 1952; Quaggio et al., 1982a, Gargantini et al., 1982; Martins, 1991, Belkacem \& Nys, 1997). A descida de $\mathrm{Ca}^{+2}$ junto ao aumento de $\mathrm{pH}$ relaciona-se à permanência de ânions bicarbonato no sistema (Martins, 1991; Wadt, 1991). O ânion bicarbonato seria responsável, também, pela neutralização do alumínio na camada subjacente (Martins, 1991; Wadt, 1991). Contudo, a permanência de ânions bicarbonato no sistema é limitada, não sendo esperada no percolado (Wadt, 1991).

O objetivo desse trabalho foi avaliar o efeito da incubação do solo com fontes de carbonato e de sulfato de cálcio na lixiviação de cátions alcalinos, alcalinos terrosos e de alumínio, sob a influência de amostras de solo coletadas sob dois tipos de vegetação (pastagem e floresta).

\section{MATERIAL E MÉTODOS}

Amostras de um Latossolo VermelhoAmarelo, álico, do município de Pirai (RJ), coletadas à profundidade de 0 a $5 \mathrm{~cm}$ sob vegetação de pastagem sobre grama batatais, Paspalum notatum $L$, e sob floresta secundária (amostras A-pastagem e A-floresta, respectivamente), foram misturadas com fontes de cálcio e colocadas a incubar em potes plásticos, sobre amostras do mesmo solo coletadas à profundidade de 200 a $250 \mathrm{~cm}$-amostras Bw (TABELA 1). Os principais minerais de argila presentes nas amostras Bw foram a caulinita e a gibsita (Wadt, 1991).

Entre as amostras da camada A e Bw foi adicionada uma camada de aproximadamente $5 \mathrm{~cm}$ de espessura de areia lavada em água deionizada para possibilitar a posterior separação das amostras. Foram adicionadas 750 e $1000 \mathrm{~g}$ de cada amostra, A e Bw, respectivamente, por pote plástico, e o solo nos potes foi compactado a uma densidade de $1,2 \mathrm{~g} \mathrm{~cm}^{-3}$ em camadas de $1 \mathrm{~cm}$ de espessura.

Os tratamentos testados foram: (a) testemunha, sem aplicação de cálcio; (b) aplicação isolada de carbonato de cálcio, eqüivalendo a $3,20 \mathrm{~g} \mathrm{CaCO}_{3} \mathrm{~kg}^{-1}$ de solo; (c) aplicação isolada de sulfato de cálcio,

TABELA 1 - Caracterização química e física de amostras de um latossolo vermelho-amarelo do município de Pirai (RJ), sob diferentes coberturas vegetais.

\begin{tabular}{|c|c|c|c|c|}
\hline \multirow[t]{2}{*}{ Características } & \multirow[t]{2}{*}{ Unidade } & \multicolumn{3}{|c|}{ 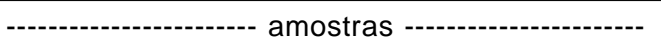 } \\
\hline & & $\begin{array}{l}\text { LVA sob } \\
\text { pastagem }\end{array}$ & $\begin{array}{l}\text { LVA sob } \\
\text { floresta }\end{array}$ & Bw \\
\hline Profundidade & $\mathrm{m}$ & 0 a 0,05 & 0 a 0,05 & 2,0 a 2,5 \\
\hline $\mathrm{Ca}^{+2}$ & $\mathrm{mmol}_{(++)} \mathrm{kg}^{-1}$ & 4,0 & 3,5 & 1,3 \\
\hline $\mathrm{Mg}^{+2}$ & $\mathrm{mmol}_{(+)} \mathrm{kg}^{-1}$ & 2,5 & 3,0 & 1,2 \\
\hline $\mathrm{K}^{+}$ & $\mathrm{mmol}_{(+)} \mathrm{kg}^{-1}$ & 1,5 & 1,4 & 0,3 \\
\hline $\mathrm{Na}^{+}$ & $\mathrm{mmol}_{(+)} \mathrm{kg}^{-1}$ & 0,4 & 0,5 & 0,1 \\
\hline $\mathrm{Al}^{+3}$ & $\mathrm{mmol}_{(+)} \mathrm{kg}^{-1}$ & 10,5 & 14,3 & 2,3 \\
\hline pH em água & $\mathrm{mmol}_{(+)} \mathrm{kg}^{-1}$ & 4,7 & 4,2 & 5,0 \\
\hline $\mathrm{pH}$ em KCl $1 \mathrm{M}$ & $\mathrm{mmol}_{(+)} \mathrm{kg}^{-1}$ & 4,0 & 3,8 & 4,5 \\
\hline $\mathrm{Al}^{+3}+\mathrm{H}^{+}$ & $\mathrm{mmol}_{(+)} \mathrm{kg}^{-1}$ & 58 & 75 & 25 \\
\hline carbono & $\mathrm{gkg}^{-1}$ & 18,0 & 25,0 & 2,0 \\
\hline argila & $\mathrm{gkg}^{-1}$ & 400 & 350 & 600 \\
\hline equiv.umidade & $\mathrm{gkg}^{-1}$ & 350 & 360 & 390 \\
\hline densidade real & $\mathrm{Mgm}^{-3}$ & 2,45 & 2,38 & 2,29 \\
\hline
\end{tabular}


eqüivalendo a $5,50 \mathrm{~g}$ de $\mathrm{CaSO}_{4} 2 \mathrm{H}_{2} \mathrm{O} \mathrm{kg}{ }^{-1}$ de solo e; (d) mistura das duas fontes de cálcio, com 2/ 3 do cálcio aplicado na forma de carbonato de cálcio e 1/3 na forma de sulfato de cálcio.

A dose de carbonato de cálcio no tratamento " $b$ " foi determinada através de experimento prévio de incubação, sendo a dose escolhida aquela suficiente para elevar $\mathrm{opH}$ do solo a valores entre 6,0 e 6,5 . As doses dos outros tratamentos foram calculadas de modo a se aplicar a mesma quantidade de equivalente de cálcio. O delineamento experimental adotado foi o inteiramente casualizado. Findo o período de incubação (48 dias), os potes foram lixiviados com $4.718 \mathrm{~cm}^{3}$ de $\mathrm{H}_{2} \mathrm{O}$ por pote (aproximadamente $7 \times 1$ volume-poro), a uma taxa média de 1,9 e desvio padrão de $0,7 \mathrm{~cm}^{3}$ minuto $^{-1}$. Estas aplicações foram feitas em sete vezes, com intervalos de uma semana entre uma e outra aplicação.

Todo volume de água aplicado foi recolhido e, após cessar a lixiviação, as soluções percoladas foram guardadas em frascos escuros, em geladeira, para posterior análise de cálcio e cálcio + magnésio, por complexometria com EDTA, utilizando-se murexida a $0,5 \%$ como indicador, potássio, por fotometria de chama, sulfato por turbidimetria e alumínio por colorimetria pelo método do aluminon (Empresa Brasileira de Pesquisa Agropecuária, 1979; Raij et al., 1987).
Nos solos de ambas as camadas, após o período de incubação e de lixiviação, foram realizadas analises de $\mathrm{pH}$ em água, cálcio e magnésio trocáveis, por $\mathrm{KCl}$ 1,0M (determinados por complexometria com EDTA, segundo Raij et al. (1987)) e, potássio assimilável, por fotometria de chama (EMBRAPA, 1979). Foram ainda determinados a acidez potencial a $\mathrm{pH} 7,0$ (EMBRAPA, 1979) e calculados o valor da soma de CAAT trocáveis, e o valor V\% (percentagem de saturação de CAAT trocáveis sobre a CTC a $\mathrm{pH}$ 7,0 do solo).

\section{RESULTADOS E DISCUSSÃO}

Nas amostras superficiais, os tratamentos com aplicação das fontes de cálcio aumentaram os teores de $\mathrm{Ca}^{+2}$ trocável, sem alterações significativas nos teores de $\mathrm{K}^{+}$e $\mathrm{Mg}^{+2}$ trocáveis (TABELA 2). Os aumentos dos teores de $\mathrm{Ca}^{+2}$ trocável deram-se às custas de uma maior CTC efetiva e, ou, por substituição com o $\mathrm{Al}^{+3}$ trocável (TABELA 2). A única exceção foi o $\mathrm{K}^{+}$trocável, na camada A-pastagem, que apresentou maior teor no solo no tratamento com carbonato de cálcio, provavelmente pela menor perda no lixiviado (TABELA 4). O valor V\% aumentou em todos os tratamentos e foi maior naquele com aplicação de maiores quantidades de carbonato (TABELA 2).

TABELA 2 - Valores médios de pH em água, valor V\% e teores de cálcio, magnésio e potássio trocável, em amostras superficiais ( 0 a $5 \mathrm{~cm}$ de profundidade) de um Latossolo Vermelho-Amarelo do município de Pirai (RJ), sob dois tipos de vegetação (floresta e pastagem), incubadas com diferentes fontes de cálcio e lixiviados com $4.718 \mathrm{~cm}^{3}$ de água destilada.

\begin{tabular}{|c|c|c|c|c|c|c|c|}
\hline \multirow[b]{3}{*}{ LVA sob pastagem: } & $\mathrm{pH}$ & $\mathrm{V}$ & $\mathrm{Ca}^{+2}$ & $\mathrm{Mg}^{+2}$ & $\mathrm{~K}^{+}$ & $\mathrm{Al}^{+3}$ & CTC ef \\
\hline & \multicolumn{2}{|c|}{ 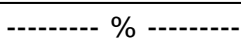 } & \multicolumn{5}{|c|}{ - } \\
\hline & & & & & & & \\
\hline testemunha & 4,59 e & 11 ef & $2,6 \mathrm{e}$ & 2,9 & $0,8 \mathrm{bc}$ & $12,3 \mathrm{~b}$ & $18,8 d$ \\
\hline carbonato de cálcio & $6,29 \mathrm{a}$ & 69 a & 42,0 a & 2,8 & $1,0 \mathrm{a}$ & $0,1 \mathrm{e}$ & $44,1 \mathrm{a}$ \\
\hline sulfato de cálcio & 4,68 e & $24 d$ & $13,1 \mathrm{~d}$ & 1,2 & $0,8 \mathrm{bc}$ & $6,5 \mathrm{c}$ & $21,8 d$ \\
\hline carbonato + sulfato & $5,84 \mathrm{~b}$ & $58 \mathrm{~b}$ & $35,5 \mathrm{~b}$ & 1,8 & $0,9 a b c$ & $0,3 \mathrm{e}$ & $38,8 \mathrm{~b}$ \\
\hline \multicolumn{8}{|l|}{ LVA sob floresta: } \\
\hline testemunha & $4,12 \mathrm{~g}$ & $08 \mathrm{f}$ & 02,7 e & 2,6 & $0,9 a b c$ & $19,2 \mathrm{a}$ & $25,7 c$ \\
\hline carbonato de cálcio & $5,51 \mathrm{c}$ & $54 \mathrm{~b}$ & $41,6 \mathrm{a}$ & 2,3 & $0,8 \mathrm{bc}$ & $0,7 \mathrm{e}$ & $45,7 \mathrm{a}$ \\
\hline sulfato de cálcio & $4,30 \mathrm{f}$ & $15 \mathrm{e}$ & $11,6 \mathrm{~d}$ & 0,9 & $0,8 \mathrm{bc}$ & $12,8 \mathrm{~b}$ & $27,5 \mathrm{c}$ \\
\hline carbonato + sulfato & $4,93 \mathrm{~d}$ & $40 \mathrm{c}$ & $30,9 \mathrm{c}$ & 1,3 & $0,8 \mathrm{bc}$ & $2,0 d$ & $35,1 \mathrm{~b}$ \\
\hline
\end{tabular}

${ }^{1}$ médias seguidas de mesma letra, dentro da mesma coluna, não diferem entre si pelo teste de Duncan ao nível de $5 \%$. 
TABELA 3 - Valores médios de pH em água, valor V\% e teores de cálcio, magnésio e potássio trocável, em amostras do horizonte Bw (200 a $250 \mathrm{~cm}$ de profundidade) de um latossolo vermelho amarelo do município de Pirai (RJ), sob dois tipos de vegetação (floresta e pastagem), incubadas com diferentes fontes de cálcio e lixiviados com $4.718 \mathrm{~cm}^{3}$ de água destilada.

\begin{tabular}{|c|c|c|c|c|c|c|c|}
\hline & $\mathrm{pH}$ & $\mathrm{V}$ & $\mathrm{Ca}^{+2}$ & $\mathrm{Mg}^{+2}$ & $\mathrm{~K}^{+}$ & $\mathrm{Al}^{+3}$ & CTC ef \\
\hline & \multicolumn{2}{|c|}{ 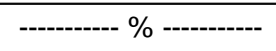 } & \multicolumn{5}{|c|}{ - mmol $k_{+}{ }^{-1}-1-1$} \\
\hline \multicolumn{8}{|l|}{ LVA sob pastagem: } \\
\hline testemunha & $4,62 d$ & $11 \mathrm{c}$ & $1,3 \mathrm{c}$ & $1,3 a b$ & 0,3 & $2,8 a b$ & $5,9 \mathrm{~d}$ \\
\hline carbonato de cálcio & $4,94 \mathrm{a}$ & $25 \mathrm{~b}$ & $5,4 \mathrm{~b}$ & $1,4 a b$ & 0,3 & $1,4 d$ & $8,6 \mathrm{c}$ \\
\hline sulfato de cálcio & $4,81 \mathrm{bc}$ & 35 a & $11,3 \mathrm{a}$ & $0,7 \mathrm{bc}$ & 0,3 & $2,6 \mathrm{~b}$ & $15,0 \mathrm{a}$ \\
\hline carbonato + sulfato & $4,95 \mathrm{a}$ & $35 \mathrm{a}$ & $11,0 \mathrm{a}$ & $1,1 \mathrm{abc}$ & 0,4 & $1,2 \mathrm{~d}$ & $14,1 \mathrm{ab}$ \\
\hline \multicolumn{8}{|l|}{ LVA sob floresta: } \\
\hline testemunha & $4,62 \mathrm{~d}$ & $11 \mathrm{c}$ & $1,5 \mathrm{c}$ & $1,8 \mathrm{a}$ & 0,3 & $3,0 \mathrm{a}$ & $6,1 \mathrm{~d}$ \\
\hline carbonato de cálcio & $4,92 a b$ & $24 b$ & $5,5 b$ & $1,0 a b c$ & 0,3 & $2,0 \mathrm{c}$ & $9,0 \mathrm{c}$ \\
\hline sulfato de cálcio & $4,75 \mathrm{c}$ & $32 \mathrm{a}$ & $10,8 \mathrm{a}$ & $0,6 \mathrm{bc}$ & 0,3 & $3,0 \mathrm{a}$ & $14,8 \mathrm{a}$ \\
\hline carbonato + sulfato & $5,16 \mathrm{~d}$ & $35 \mathrm{a}$ & $10,5 \mathrm{a}$ & $0,4 \mathrm{c}$ & 0,3 & $1,5 \mathrm{~d}$ & $12,9 \mathrm{~b}$ \\
\hline
\end{tabular}

${ }^{1}$ médias seguidas de mesma letra, dentro da mesma coluna, não diferem entre si pelo teste de Duncan ao nível de $5 \%$.

A aplicação das fontes de cálcio apresentou efeito pequeno sobre os teores de $\mathrm{K}^{+}$ trocável na camada $B$ (TABELA 3). Em relação à testemunha, na camada $B$-floresta houve diminuição do $\mathrm{Mg}^{+2}$ trocável no tratamento carbonato + sulfato e, aumento do teor de $\mathrm{Ca}^{+2}$ trocável em todos os tratamentos (TABELA 3). $\mathrm{Na}$ camada B-floresta e B-pastagem, na aplicação isolada de sulfato de cálcio, o aumento do teor de $\mathrm{Ca}^{+2}$ trocável, da CTC efetiva e do valor V\% foram independentementes da neutralização da acidez do solo (TABELA 3), o que Wadt (1991) atribuiu à geração de novos sítios de troca.

A aplicação de sulfato de cálcio na forma isolada favoreceu a percolação de cátions de uma forma geral e de cátions alcalinos e alcalinos terrosos (TABELA 4), havendo, inclusive, lixiviação de $\mathrm{K}^{+}$(somente nas colunas de solo $\mathrm{A} / \mathrm{B}$ pastagem) e $\mathrm{Mg}^{+2}$ (ambas as colunas de solos) à quantidades superiores ao da testemunha (TABELA 4), mesmo com os solos apresentando baixos níveis de $\mathrm{Mg}^{+2}$ e $\mathrm{K}^{+}$na forma trocável (TABELAS 2 e 3).

Por sua vez, a aplicação de carbonato de cálcio, tanto isolada como em mistura, foi efetiva em diminuir a movimentação descendente de $\mathrm{K}^{+}$à níveis mais baixos que na testemunha (TABELA 4), não afetando a quantidade de $\mathrm{Mg}^{+2}$ recolhida no lixiviado (TABELA 4). A baixa solubilidade do carbonato de cálcio, limitando o aumento da atividade de $\mathrm{Ca}^{+2}$ na solução do solo, tornando pouco efetivo seu poder de troca por ação de massa e, a diminuição da atividade dos prótons pela presença do carbonato, liberando os sítios de troca, poderiam explicar tanto a maior retenção de $\mathrm{K}^{+2}$ (TABELA 2) como a incapacidade do $\mathrm{Ca}^{+2} \mathrm{em}$ expulsar $\circ \mathrm{Mg}^{+2} \mathrm{e} \circ \mathrm{K}^{+2}$ (TABELA 4). Portanto, parece que o aumento de $\mathrm{Ca}^{+2}$ no complexo sortivo da camada $A$ de ambos os solos deu-se graças à diminuição da atividade dos íons hidrogênio, e não somente pela força da ação de massa dos íons $\mathrm{Ca}^{+2}$ adicionados ao sistema.

As colunas dos solos pastagem e floresta diferiram quanto à capacidade de reter $0 \mathrm{~K}^{+2}$ (TABELA 5). Considerando que ambos os solos da camada $A$ foram coletados de uma distância máxima de 50m, no mesmo local, diferindo apenas quanto ao tipo de cobertura vegetal; portanto, possuindo a mesma mineralogia e teor de argila entre 35 a $40 \%$, a maior retenção do potássio na coluna de solos sob pastagem poderia ser atribuída à energia de ligação do íon $\mathrm{K}^{+}$com as superfícies coloidais: a presença de maior número de prótons em torno da superfície dos colóides na camada Afloresta, inferido a partir do menor pH da suspensão solo:água e do maior teor de matéria orgânica neste solo, poderia dificultar a aproximação dos íons potássio a essas superfícies, diminuindo assim a energia de ligação do potássio com os grupamentos ionizados. Neste mesmo sentido, Mota et al. (1996) demonstraram que $\mathrm{Ca}^{+2}$ foi capaz de diminuir a complexação de $\mathrm{Pb}^{+2}$ pelo humus do solo, através 
TABELA 4 - Quantidade total de $\mathrm{Ca}^{+2}, \mathrm{Mg}^{+2}, \mathrm{~K}^{+}, \mathrm{Al}^{+3}, \mathrm{SO}_{4}^{-2}$, Cátions (Al+Ca+Mg+K) e CAAT $(\mathrm{Ca}+\mathrm{Mg}+\mathrm{K})$, recolhidos no percolado, em $10^{-3} \mathrm{cmol}^{2} \mathrm{e}$, relações entre as quantidades totais de $\mathrm{CAAT} / \mathrm{SO}_{4}{ }^{-2}$ (CAAT/S), $\mathrm{Al}^{+3} / \mathrm{SO}_{4}{ }^{-2}$ (Al/S) e CAAT/Al ${ }^{+3}$ (CAAT/Al) lixiviadas, do $2^{\circ}$ ao $7^{\circ}$ volume-poro, em colunas com amostras de um latossolo vermelho-amarelo do município de Pirai (RJ), sob dois tipos de vegetação (floresta e pastagem), incubadas com diferentes fontes de cálcio.

\begin{tabular}{|c|c|c|c|c|c|c|c|}
\hline Tratamentos & {$\left[\mathrm{Ca}^{+2}\right]$} & {$\left[\mathrm{Mg}^{+2}\right]$} & {$\left[\mathrm{K}^{+}\right]$} & {$\left[\left.\mathrm{A}\right|^{+3}\right]$} & {$\left[\mathrm{SO}_{4}^{-2}\right]$} & [Cátions] & [CAAT] \\
\hline & & & & $-\mathrm{mr}$ & & & ---- \\
\hline \multicolumn{8}{|l|}{ LVA sob pastagem. } \\
\hline testemunha & $9,2 \mathrm{c}$ & $0,9 \mathrm{~b}$ & $4,7 \mathrm{~b}$ & $1,5 \mathrm{c}$ & $5,1 \mathrm{c}$ & $16,5 \mathrm{c}$ & $14,9 \mathrm{c}$ \\
\hline carbonato de cálcio & $23,9 \mathrm{c}$ & $0,5 \mathrm{~b}$ & $3,4 \mathrm{c}$ & $1,9 \mathrm{~b}$ & $4,3 \mathrm{c}$ & $29,9 \mathrm{c}$ & $27,9 \mathrm{c}$ \\
\hline sulfato de cálcio & 219,1 a & $3,5 \mathrm{a}$ & $6,14 \mathrm{a}$ & $0,9 \mathrm{~d}$ & $263,4 a$ & 229,7 a & $228,8 \mathrm{a}$ \\
\hline carbonato + sulfato & $70,0 \mathrm{~b}$ & $0,9 \mathrm{~b}$ & $3,36 \mathrm{c}$ & $0,8 \mathrm{~d}$ & $48,5 \mathrm{~b}$ & $75,2 \mathrm{~b}$ & $74,4 \mathrm{~b}$ \\
\hline \multicolumn{8}{|l|}{ LVA sob floresta. } \\
\hline testemunha & $11,6 \mathrm{c}$ & $1,2 \mathrm{~b}$ & 5,69 a & $1,9 \mathrm{~b}$ & $5,9 \mathrm{c}$ & $20,5 \mathrm{c}$ & $18,6 \mathrm{c}$ \\
\hline carbonato de cálcio & $31,4 \mathrm{c}$ & $0,8 \mathrm{~b}$ & $4,51 \mathrm{~b}$ & $2,9 \mathrm{a}$ & $5,1 \mathrm{c}$ & $39,8 \mathrm{c}$ & $36,8 \mathrm{c}$ \\
\hline sulfato de cálcio & 225,2 a & $3,8 \mathrm{a}$ & $5,72 \mathrm{a}$ & $0,6 \mathrm{~d}$ & $277,2 \mathrm{a}$ & 235,4 a & $234,7 \mathrm{a}$ \\
\hline carbonato + sulfato & $65,7 \mathrm{~b}$ & $1,8 \mathrm{~b}$ & $4,13 \mathrm{~b}$ & $0,7 \mathrm{~d}$ & $51,3 \mathrm{~b}$ & $72,3 \mathrm{~b}$ & $71,6 \mathrm{~b}$ \\
\hline
\end{tabular}

${ }^{1}$ médias seguidas de mesma letra, para cada uma das três primeiras colunas, não diferem entre si pelo teste de Duncan ao nível de $5 \%$.

TABELA 5 - Média das quantidades totais de potássio $\left(\left[\mathrm{K}^{+}\right]\right)$recolhida no lixiviado, em mmolc, das colunas de solo dos tratamentos com amostras de solo coletadas sob pastagem ou sob floresta.

\begin{tabular}{cl}
\hline Colunas de solo com amostras de: & {$\left[\mathrm{K}^{+}\right]^{\star *}$} \\
\hline Pastagem & $17,6 \mathrm{a}$ \\
Floresta & $20,0 \mathrm{~b}$ \\
\hline
\end{tabular}

** Médias seguidas de mesma letra, na mesma coluna, não diferem entre sí pelo teste de Duncan a $1 \%$ de probabilidade.

da diminuição do número de sítios disponíveis para a formação de complexos, sem apresentar, em contrapartida, qualquer efeito de diminuição das cargas disponíveis para a complexação. A adsorção de CAAT $\left(\mathrm{Na}^{+}, \mathrm{K}^{+}, \mathrm{Mg}^{+2}, \mathrm{Ca}^{+2}\right)$ pelas substâncias húmicas também parece serem devidas à adsorção iônica, porém com pequeno grau de seletividade (Tipping et al., 1995), sugerindo que os íons hidrogênio seriam adsorvidos preferencialmente em relação ao $\mathrm{K}^{+}$.

Paralelamente à menor movimentação de $\mathrm{K}^{+}$no tratamento carbonato de cálcio, houve o favorecimento à lixiviação de $\mathrm{Al}^{+3}$ (TABELA 4).
Jucksch et al. (1986) em um estudo de dispersão de argilas atribuiram a maior percolação de $\mathrm{Al}^{+3}$ ao arraste mecânico de particulas em função do efeito da dispersão de argilas. Contudo, este fenômeno provavelmente não ocorreu no presente estudo, visto a maior percolação de $\mathrm{Al}^{+3}$ ter ocorrido em maior proporção no tratamento carbonato de cálcio nas colunas do solo floresta, que apresentaram os menores valores de $\mathrm{pH}$, em relação ao mesmo tratamento nas colunas de solo pastagem (TABELA 2). Adicionalmente, o pH do solo acima de 5,5 no tratamento carbonato + sulfato, no solo $A / B$ - pastagem, não favoreceu a percolação de $\mathrm{Al}^{+3}$ (TABELAS 2 e 4), indicando também a impossibilidade de estar havendo arraste mecânico de particulas conforme foi sugerido no trabalho de Jucksch et al. (1986).

Outra possibilidade seria a aplicação de $\mathrm{SO}_{4}^{-2}$ favorecendo a movimentação descendente de $\mathrm{Al}^{+3}$ (Pavan et al., 1984). Esta hipótese também pode ser descartada neste trabalho, visto que a lixiviação de $\mathrm{Al}^{+3}$ foi inversamente proporcional às quantidades de de $\mathrm{SO}_{4}^{-2}$ recolhidas no lixiviado (Figura 1). Além disto, na ausência da aplicação de sulfato, as maiores quantidades de $\mathrm{Al}^{+3}$ ocorreram com o aumento da proporção $\mathrm{Al}^{+3} / \mathrm{SO}_{4}^{-2}$, sugerindo que $0 \mathrm{SO}_{4}^{-2}$ não seria o principal ânion acompanhante, ao menos 
nas condições deste trabalho (Figura 2). Já as quantidades dos demais cátions recolhidos no lixiviado foram diretamente proporcionais às de $\mathrm{SO}_{4}$ ${ }^{2}$, sugerindo ser o sulfato o principal ânion acompanhante neste caso (Figura 3).

As maiores quantidades de $\mathrm{Al}^{+3}$ no lixiviado não podem ser atribuídas simplesmente à presença de $\mathrm{HCO}_{3}^{-}$, pois, as quantidades lixiviadas nas testemunhas das colunas de solo floresta e

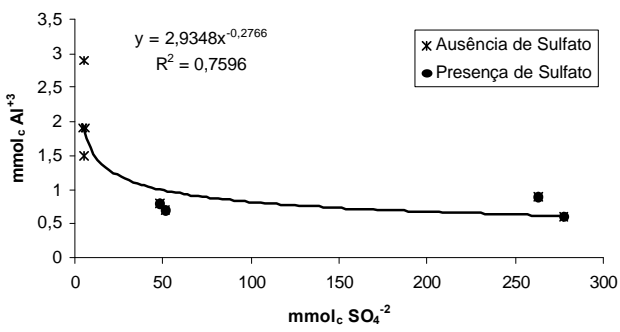

Figura 1 - Relação entre as quantidade de $\mathrm{Al}^{+3}$ e de $\mathrm{SO}_{4}^{-2}$ recolhidas nos lixiviados dos tratamentos com presença ou ausência de sulfato de cálcio.

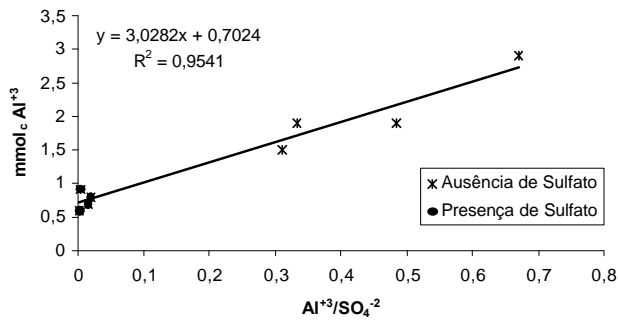

Figura 2 - Relação entre as quantidades de $\mathrm{Al}^{+3}$ recolhidas e a razão $\mathrm{Al}^{+3} / \mathrm{SO}_{4}^{-2}$ nos lixiviados dos tratamentos com presença ou ausência de sulfato de cálcio.

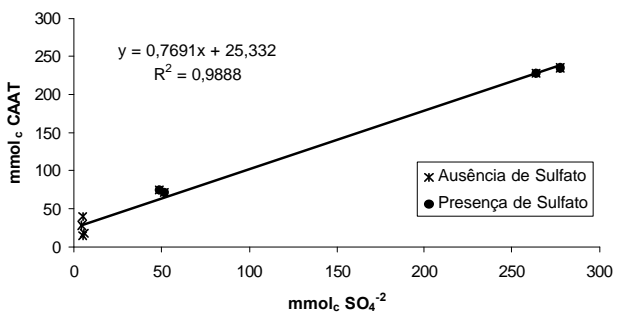

Figura 3 - Relação entre a quantidade total de CAAT (cátions alcalinos e alcalinos terrosos) e de $\mathrm{SO}_{4}^{-2}$ recolhidos nos lixiviados dos tratamentos com presença ou ausência de sulfato de cálcio. pastagem foram próximas àquelas observadas nos tratamentos com aplicação de carbonato de cálcio. Por este motivo, supõe-se que ânions orgânicos seriam os responsáveis pela lixiviação do $\mathrm{Al}^{+3}$ (Wadt, 1991), através de mecanismos semelhantes àqueles observados em podzois sob condições naturais ou pela aplicação de quelantes sintéticos como o EDTA (Hern et al., 1988), embora, quimicamente, tenha-se encon-trado que a afinidade de $\mathrm{Al}^{+3}$ por ácidos fúlvicos não aparente ser maior que a de complexantes fracos, como o ácido acético (Yong \& Bache, 1985).

Desta forma, para o solo em estudo, o processo de lixiviação de cátions poderia ser determinado pela resultante da força de adsorção do cátion com a superfície dos colóides do solo e do cátion com o seu respectivo ânion acompanhante. Da mesma forma, no processo de lixiviação de ânions seriam necessário considerar a resultante da força de adsorção do ânion com a superfície coloidal do solo e do ânion com o seu respectivo câtion acompanhante.

Dentre os cátios estudados, aqueles que seriam fracamente adsorvidos pelos colóides do solo $\left(\mathrm{K}^{+}, \mathrm{Mg}^{++}\right)$poderiam lixiviar mesmo na presença de ânions que formem ligações fracas, como cloretos e sulfatos (Processo 1 da Figura 4). Além disto, quanto menor a força de adsorção entre o ânion e o superfície dos colóides do solo, haveria maior favorecimento para a lixiviação do cátion acompanhante. Por esta razão os ânions $\mathrm{Cl}^{-}$ apresentam-se com maior mobilidade que os ânions $\mathrm{SO}_{4}^{-2}$ (Dal Bó et al., 1986). Variações nas características eletroquímicas dos coloides do solo, como aquela decorrente da nuvem de prótons em torno das substâncias húmicas, poderiam diminuir a aproximação do cátion com o solo e facilitar sua lixiviação, conforme sugerido nesse trabalho para $\mathrm{K}^{+}$. Mesmo a lixiviação de $\mathrm{Ca}^{+2}$ acompanhando o ânion sulfato somente deveria ocorrer após a saturação do complexo de troca com $\mathrm{Ca}^{+2}$ atingir o equilíbrio em que a força de atração de um novo íon de cálcio no complexo sortivo fosse menor que a força de atração do cálcio pelo ânion acompanhante (Processo 1, Figura 4). Por exemplo, Pearce \& Sumner (1997) atribuiram à "adsorção de sais" a razão pela menor mobilidade do sulfato no solo, em relação ao cloreto. Bellini et al. (1996) também relatam perda de mobilidade de $\mathrm{NO}_{3}^{-}$e de $\mathrm{Cl}^{-}$em razão da adsorção destes ânions pelas superfícies coloidas dos solos.

Por outro lado, cátions que apresentam mais elevada força de adsorção, como o alumínio, teriam sua lixiviação limitada à presença de um ânion acompanhante capaz de complexar o íon 

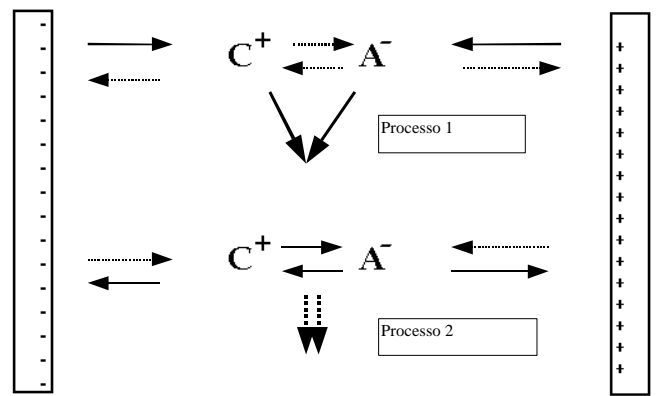

Figura 4 - Modelos simplificados de dois possíveis processos controlando os processos de lixiviação de cátions e ânions em solos. Processo 1: baixa energia de adsorção dos íons pelas superfícies coloidais do solo e intensa taxa de lixiviação. Processo 2: alta energia de adsorção dos íons pelas superfícies coloidais do solo e baixa taxa de lixiviação. Os íons envolvidos em cada um dos processos dependerá da natureza da superfície adsorvente. Nos solos utilizados neste estudo, com predominância de caulinita e gibsita na fração argila, os íons envolvidos no Processo 1 foram magnésio, potássio, cálcio e sulfato e, no Processo 2, foram alumínio e, provavelmente, substâncias húmicas presentes na solução do solo.

metálico (Processo 2, Figura 4). Nesse caso, a lixiviação ocorreria enquanto a força de complexação fosse maior que as forças de adsorção e, ou, precipitação. São exemplos desse mecanismo o processo de lixiviação de alumínio usando-se EDTA como íon acompanhante (Hern et al., 1988), e, possívelmente, o ocorrido neste trabalho com o tratamento com carbonato de cálcio, resultando em liberação de substâncias orgânicas pelo aumento do $\mathrm{pH}$.

Estes processos, embora genéricos, sugerem que na utilização de fontes de cálcio, quando for necessária a correção dos níveis de cálcio trocável nos subsolos deficientes neste elemento, deve-se levar em consideração não apenas as características de solubilidade e reações químicas dos produtos aplicados, mas também as características eletroquímicas das superficies coloidais do solo.

\section{CONCLUSÕES}

A aplicação de sulfato de cálcio foi efetiva em promover aumentos no teor de cálcio em profundidade, no entanto, deve ser utilizada junto com carbonato de cálcio para que não provoque movimentações descendentes excessivas de outros cátions alcalinos ou alcalinos terrosos, além do cálcio.

O aumento do teor de cálcio trocável na ausência de sulfato de cálcio deu-se praticamente as custas do deslocamento de prótons e alumínio do complexo de troca para a solução do solo, em decorrência do aumento do $\mathrm{pH}$ do solo pela presença de carbonato.

$\mathrm{Na}$ presença de sulfato de cálcio, o aumento do teor de cálcio trocável foi principalmente devido à competição do cálcio com outros íons presentes no complexo de troca, resultando do deslocamento desses íons para a solução do solo, por ação de massa.

A lixiviação de potássio e magnésio, nos tratamentos com aplicação isolada de sulfato de cálcio, foram intensas embora não tenham sido percebidas pela análise dos teores destes cátions na forma trocável. Maior percolação de potássio em solos com maior teor de matéria orgânica e menor $\mathrm{pH}$ sugere uma menor afinidade desse cátion em sistemas onde haja o favorecimento a uma maior protonação da superfície dos colóides.

\section{AGRADECIMENTOS}

Ao CNPq, pelo auxílio financeiro e parte da bolsa de estudos e à CAPES por parte da bolsa de estudos.

\section{REFERÊNCIAS BIBLIOGRÁFICAS}

BELKACEM, S.; NYS, C. Effects des formes et doses d'amendements et de gypse sur les caracteristiques chimiques et les percolats d'un sol forestier acide. Annales des Sciences Forestieres, v.54, p.169-180, 1997.

BELLINI, G.; SUMNER, M.E.; RADCLIFFE, D.E.; OAFOKU, N.P. Anion transport through columns of highly weathered acid soil: adsorption and retardation. Soil Science Society of America Journal, v.60, p.132-137, 1996.

DAL BÓ, M.A.; RIBEIRO, A.C.; COSTA, L.M.; THIÉBAUT, J.T.L. ; NOVAIS, R.F. Efeito da adição de diferentes fontes de cálcio em colunas de solo cultivadas com cana-de-açúcar: I. Movimentação de bases no solo. Revista Brasileira de Ciência do Solo, v.10, p.195-198, 1986. 
EMPRESA BRASILEIRA DE PESQUISA AGROPECUÁRIA. Manual de métodos de análise de solo. Rio de Janeiro: Serviço Nacional de Levantamento e Conservação de Solos, 1979, $1 \mathrm{v}$.

GARGANTINI, H.; MELLO, F.A.F.; ARZOELA, S. Efeitos da calagem sobre os teores de cálcio mais magnésio de perfis de solos de cerrado. Anais da ESALQ, v.39, p.1115-1136, 1982.

HERN, J.L.; MENSER, H.A.; SIDLE. R.C.; STALE, T.E. Effects of surface-applied lime and EDTA on subsoil acidity and aluminium. Soil Science, v.145, p.52-57, 1988.

JUCKSCH, I.; COSTA, L.M.; MOURA FILHO, W.; RIBEIRO, A.C.; SOPRANO, E. Efeito da calagem na dispersão de argila em um latossolo vermelhoescuro. Revista Ceres, v.33, p.456-460, 1986.

McLAY, C.D.A.; RITCHIE, G.S.P.; POSTER, W.M.; CRUSE, A. Amerioration of subsurface acidity in sandy soils in low rainfall regions. II. Changes to soil solutions composition following the surface application of gypsum and lime. Australian Journal of Soil Research, v.32, p.847-865, 1994.

MARTINS, O.C. Comportamento da soja e do trigo e alterações no perfil do solo em resposta à aplicação de diferentes misturas de calcário e gesso. Viçosa, 1991. 81p. Dissertação (Mestrado) - Universidade Federal de Viçosa.

MOTA, A.M.; RATO, A.; BRAZIA, C.; SIMÕES GONÇALVES, M.L. Competition of $\mathrm{Al}^{+3}$ in complexation of humic matter with $\mathrm{Pb}^{+2}$ : a comparative study with other ions. Environmental Science and Techonology, v.30, p.1970-1974, 1996.

PAVAN, M.A.; BINGHAM, F.T.; PRATT, P.F. Redistribution of exchangeable calcium, magnesium, and aluminum following lime or gypsum applications to a Brazilian Oxisol. Soil Science Society of America Journal, v.48, p.33-38, 1984.

PEARCE, R.C.; SUMNER, M.E. Apparent salt sorption reactions in a unfertilized acid subsoil. Soil Science Society of America Journal, v.61, p.765-772, 1997.

QUAGGIO, J.A.; DECHEN, A.R.; RAIJ, B. van. Efeitos da aplicação de calcário e gesso sobre a produção de amendoim e a lixiviação de bases no solo. Revista Brasileira de Ciência do Solo, v.6, p.189-194, 1982a.

QUAGGIO, J.A.; MASCARENHAS, H.A.A.; BATAGLIA, O.C. Resposta da soja à aplicação de doses crescentes de calcário em latossolo roxo distrófico de cerrado. II. Efeito residual. Revista Brasileira de Ciência do Solo, v.6, p.113-118, 1982b.
RAIJ, B. van; CANTARELLA, H.; CAMARGO, A.P. SOARES, E. Perdas de cálcio e magnésio durante cinco anos em ensaio de calagem. Revista Brasileira de Ciência do Solo, v.6, p.33-37, 1982.

RAIJ, B. van; QUAGGIO, J.A.; CANTARELLA, H.; FERREIRA, M.E.; LOPES, A.S.; BATAGLIA, O.C. Análise química do solo para fins de fertilidade. Campinas: Fundação Cargill, 1987. $170 p$.

REEVE, N.G.; SUMNER, M.E. Amelioration of subsoil acidity in Natal oxisols by leaching of surface-applied amendments. Agrochemophysica, v.4, p.1-5, 1972.

RIRIE, D.; TOTH, S.J.; BEAR, F.E. Movement and effect of lime and gypsum in soil. Soil Science, v.73, p..23-35, 1952.

RITCHEY, K.D.; SILVA, J.E.; SOUSA, D.M.G. Relação entre teor de cálcio no solo e desenvolvimento de raízes avaliado por um método biológico. Revista Brasileira de Ciência do Solo, v.7, p.269-275, 1983.

RITCHEY, K.D.; SOUSA, D.M.G.; LOBATO, E.; CORREA, O. Calcium leaching to increase rooting depth in a Brazilian Savannah Oxisol. Agronomy Journal, v.72, p.40-44, 1980.

SUMNER, M.E.; SHAHADNDEH, H.; BOUTON, J.; HAMMEL, J. Amelioration of an acid soil profile through deep liming and surface application of gypsum. Soil Science Society of America Journal, v.50, p.1254-1258, 1986.

TIPPING, E.; BERGGEN, D.; MULDER, J.; WOOF, C. Modelling the solid-solution distributions of protons, aluminium, base cations and humic substances in acid soils. European Journal of Soil Science, v. 46, p.77-94, 1995.

WADT, P.G.S. Movimentação de cátions em latossolo vermelho-amarelo, álico, incubado com carbonato e sulfato de cálcio, isolados ou misturados. Itaguai, 1991. 174 p. Dissertação (Mestrado) Universidade Federal Rural do Rio de Janeiro.

YONG, S.D.; BACHE, B.W. Aluminium-organic complexation: formation constants and a speciation model for soil solution. Journal of Soil Science, v.36, p.261-269, 1985.

Recebido para publicação em 07.01.98

Aceito para publicação em 12.07.99 